Research Article

\title{
Experimental and Numerical Studies on the Mechanical Properties of Columnar Jointed Basalt
}

\author{
Shiyi Zhu $\mathbb{D},{ }^{1,2}$ Changdi He $\mathbb{D},{ }^{1}$ Fei Peng $\mathbb{D}^{1},{ }^{1}$ Anchi Shi, ${ }^{3}$ Dongyang Yuan $\mathbb{D}^{1}$, \\ and Weikang Zhang ${ }^{1}$ \\ ${ }^{1}$ Institute of Bridge and Tunnel Engineering, Zhejiang Scientific Research Institute of Transport, Hangzhou 310023, China \\ ${ }^{2}$ Geotechnical Research Institute, Hohai University, Nanjing 210098, China \\ ${ }^{3}$ PowerChina Huadong Engineering Corporation Limited, Hangzhou 311122, China
}

Correspondence should be addressed to Changdi He; chardy@csu.edu.cn

Received 17 October 2020; Revised 9 November 2020; Accepted 19 November 2020; Published 3 December 2020

Academic Editor: Zhigang Tao

Copyright (c) 2020 Shiyi Zhu et al. This is an open access article distributed under the Creative Commons Attribution License, which permits unrestricted use, distribution, and reproduction in any medium, provided the original work is properly cited.

Columnar jointed basalts (CJB) are featured by the joint network of discontinuities, which is hard for geotechnical design and construction. Therefore, investigating the mechanical behaviors of CJB is significant for the long-term use of the engineering structures. In this paper, field research studies, such as the rigid bearing plate tests and acoustic tests, were employed, to obtain the deformation modulus and the acoustic velocity of columnar jointed basalts, and the formula expressed by deformation modulus and acoustic velocity was then established, which would be a useful guidance for the site operation. Based on the monitoring and testing data of CJB, several numerical simulation models with different joint angles and weak thickness were built to further discuss the mechanical behaviors of CJB. The numerical simulation results show that the joint angle of $30^{\circ} \sim 60^{\circ}$ presents weak antipressure abilities, for the shearing slipping force and interformational sliding are remarkable in them. Besides, the small material property difference is helpful for the compressive strength of rock masses. After adopting the most unfavorable joint angle and width to model the tunneling process in CJB, it suggests that it is easily damaged along the directions of rock joints in CJB when constructing in tunnels.

\section{Introduction}

The columnar jointed basalts (CJBs) are particular geological structures formed during the cooling of basalt, which usually cut basalt into regular or irregular prisms. Due to the internal implicit joints and unloading cracks in CJB, the mechanical properties of rock masses are complicated. It was discovered that during the excavation of $\mathrm{CJB}$, the special failure patterns and mechanical responses normally occurred [1-4]. In China, the columnar jointed basalts are widely distributed at several regions, which create great challenges for the design and construction of engineering projects, such as the tunnels, mines, and dams [5], for their special jointing patterns [6].

Therefore, investigating the mechanical behaviors of $\mathrm{CJB}$ has become urgent matters in recent years due to their particular damage modes and mechanical behaviors during the CJB tunneling and excavation, which poses adverse effects on project stability. For example, in tunnel projects, during the excavation process of underground tunnels in $\mathrm{CJB}$, collapses may easily occur due to their unfavorable mechanical properties [7-10]; in dam projects, the dam foundation bears substantial hydraulic pressure during the operation period, but rock mass materials of the dam foundation are normally prone to failure due to excavation and mechanical loading, especially in CJB geological conditions $[11,12]$. Hence, evaluating the mechanical properties and construction stability of CJB is necessary and essential [13]. After a review of related studies, it shows that there are several approaches to implement related work, such as field surveys [14], experimental tests, and numerical simulations [15-17]. Most of the scholars combined both methods to carry out the scientific research studies.

Several field investigations were employed in the areas where columnar jointed basalts occur [18]. The affecting factors of mechanical properties of columnar jointed basalts 
primarily contain the distribution of internal joints, geological environment [19-22], pore water pressure [23], and climatic conditions. A uniform distribution survey line method was put forward to reveal the structure, deformation, and failure characteristics from formation to their exposed state of CJB [24].

Experimental tests contain two types which are in situ tests and laboratory tests [25]. In situ tests are the most normal and conventional way in determining the parameters of rock masses. In situ testing methods, such as field triaxial tests, plate bearing tests, microseismic monitoring technologies, and acoustic tests [26], have been widely employed, and a number of research achievements are reported. Carrying out field tests shows that rock mass time-dependent relaxation, cracking, and collapse are dramatic features in CJB [27]. Laboratory tests on rock mass and physical modeling tests have been conducted as well [28-30], to evaluate mechanical behavior and failure mechanisms $[31,32]$. Limited by the scale of laboratory tests, field tests become an effective way to confirm mechanical properties of rock masses. Observation window methods, 3D scanning methods, and P-wave tests were employed to study the features of internal implicit joints of CJB at drainage tunnels, and it suggested that the CJB is heterogeneous, showing the characteristics of mosaic structure and mainly quadrilateral in shape, and the joints are distributed with distinct tendency, which could influence the P-wave anisotropy of CJB. Besides, the artificial CJB specimens were made to conduct the uniaxial compression tests, and the anisotropic deformation strength was discussed. Scanning electron microscope (SEM) tests were also adopted to analyze the mechanical behaviors and microscopic failure of rock masses, which indicated that the confining pressure is essential for the mechanical behaviors of the rock masses [33].

Numerical simulation methods are quick and effective approaches to investigate the mechanical behaviors of CJB. A novel geometric modeling method based on the topological properties of field columnar basalt was employed, which provided a method to estimate rock mass modulus using numerical simulation. 3DEC was used to simulate the uniaxial compression tests, which indicated that the elasticplastic and elastic brittle behaviors are different with the presence of confining pressure [15, 34, 35]. Chen et al. [36] adopted $\mathrm{PFC}^{3 \mathrm{D}}$ to investigate the effect of the joint inclination on the mechanical behavior and associated cracking process and displacement. A modified constrained centroid Voronoi tessellation (CCVT) algorithm was put forward to analyze the influence of columnar jointed structure on the mechanical properties of CJB. Zhou et al. [37] addressed a statistical damage model based on the Weibull distribution considering the joint orientation associated with Jaeger's and modified Hoek-Brown failure criteria for CJB, and the discrete element method of PFC was employed to verify the model proposed. A computational interaction algorithm with high numerical accuracy and efficiency under the loading conditions of plasticity, damage, and coupled elastoplastic damage was developed.

As a consequence, the objective of this paper is to investigate the mechanical behaviors of CJB. Firstly, field research studies were conducted in the engineering project, where the CJB was widely distributed. The in situ research studies mainly contained the rigid bearing plate tests and acoustic tests on columnar jointed basalts, to study the particular mechanical properties of CJB. Secondly, based on the field testing data, the formula between deformation modulus and acoustic velocity was established. For the further discussion of the mechanical properties of CJB, several numerical simulation models with different joint angles and widths were built. After confirming the most unfavorable joint angle and width of CJB, an engineering example about tunneling in CJB with the most adverse geological conditions was modeled.

\section{Engineering Background}

The Baihetan hydropower station contains a super-high arch dam, whose height is $289 \mathrm{~m}$, and it is built in the southwest of China. Furthermore, it is also the second largest hydropower station around the world, whose installed capacity is $16000 \mathrm{MW}$. Figure 1(a) depicts the topographical range of Baihetan arch dam, and it can be seen that Baihetan arch dam is constructed in an asymmetrical V-shaped valley, whose left slope is gentle and the right slope is steep. The width of the river valley is from $449 \mathrm{~m}$ to $534 \mathrm{~m}$ at the normal pool level. Figure 1(b) illustrates the geological condition along the dam axis, which shows that the rock masses at the dam site mainly contain Permian Emeishan basalt and breccia lava with 11 layers of basalt, i.e., $\mathrm{P}_{2} \beta_{1}-\mathrm{P}_{2} \beta_{11}$. Besides, the faults and shear belts are in wide distribution, $\mathrm{F}_{17}$ is the largest fault region in the left slope, the $\mathrm{F}_{14}$ and $\mathrm{F}_{16}$ extend across the riverbed close to the right slope. The interlayer shear belts are widely developed on the top of each basalt layer, for example, $\mathrm{C}_{3}$ and $\mathrm{C}_{3-1}$ are located at the left slope from the elevation of $720 \mathrm{~m}$ to $760 \mathrm{~m}, \mathrm{C}_{3}, \mathrm{C}_{3-1}, \mathrm{C}_{4}$, and $\mathrm{C}_{5}$ in the right side of the dam are distributed from the elevation of $640 \mathrm{~m}$ to $780 \mathrm{~m}$. Some intrastratal shear belts, such as $\mathrm{Ls}_{331}$, $\mathrm{Ls}_{3318}, \mathrm{Ls}_{3319}, \mathrm{Rs}_{331}$, and $\mathrm{Rs}_{336}$, mainly reveal in the third basalt stratum, which are $\mathrm{P}_{2} \beta_{3}^{2-2}$ and $\mathrm{P}_{2} \beta_{3}^{3}$. The range of dam foundation on the left bank of the Baihetan hydropower station refers to the elevation of the left bank is $600 \sim 834 \mathrm{~m}$, the range of dam foundation on the right bank is $600 \sim 834 \mathrm{~m}$, the range of dam foundation on the riverbed refers to the elevation of both river banks is below 600, and the lowest elevation of the dam foundation is $545 \mathrm{~m}$.

Figure 2 shows the field images of different types of rock masses in Baihetan arch dam, there are three kinds of rock masses, i.e., columnar jointed basalt (CJB), breccia lava, and cryptic basalt. The columnar jointed basalt (CJB) is looser than other two rock masses; thus, the anisotropy is more significant. However, the columnar jointed basalt (CJB) is a common primary structure in basalt, and it extensively spreads in the Baihetan hydropower station. The CJB can be divided into three types, which mainly conclude Category-I CJB, Category-II CJB, and Category-III CJB, and they are depicted in Figure 1(b) [14]. The columnar jointed basalts are primarily located in $\mathrm{P}_{2} \beta_{2}^{2}, \mathrm{P}_{2} \beta_{2}^{3}, \mathrm{P}_{2} \beta_{3}^{2}, \mathrm{P}_{2} \beta_{3}^{3}, \mathrm{P}_{2} \beta_{4}^{1}, \mathrm{P}_{2} \beta_{6}^{1}$, $\mathrm{P}_{2} \beta_{7}^{1}$, and $\mathrm{P}_{2} \beta_{8}^{2}$, and they are nonuniform with different columnar size and length. Meanwhile, in the riverbed and 


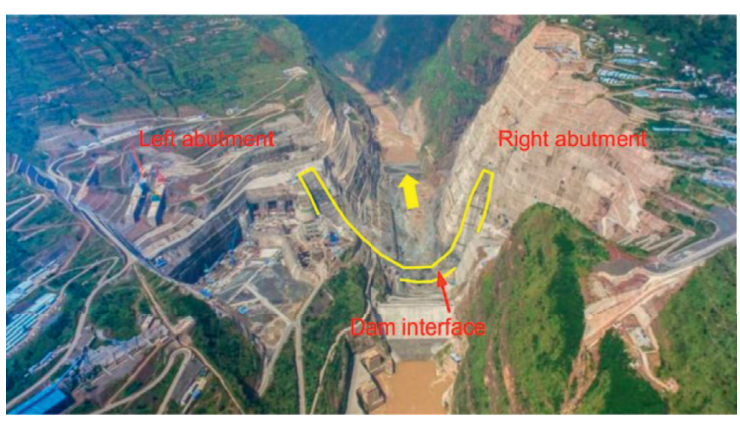

(a)

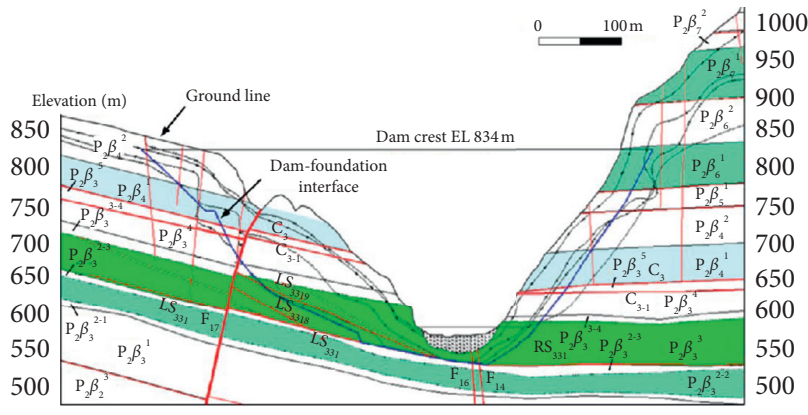

Category-I CJB

Category-II CJB

Category-III CJB

(b)

FIgURE 1: Topographical and geological conditions of Baihetan arch dam: (a) topographical conditions at the dam site; (b) geological profile along the dam axis $[2,34]$.

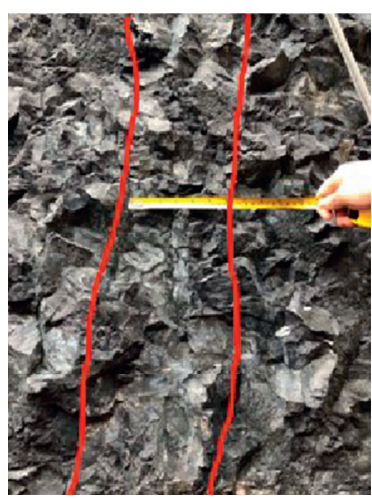

(a)

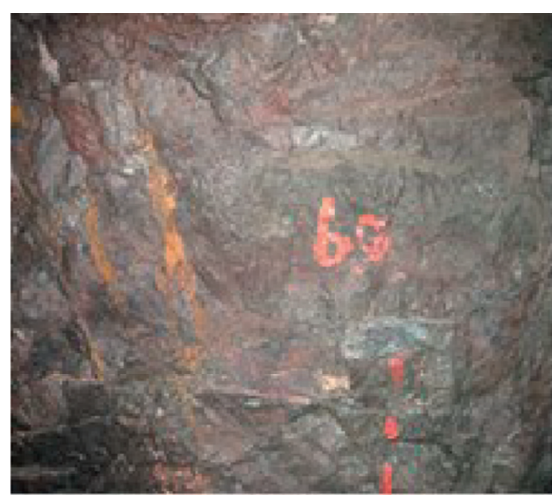

(b)

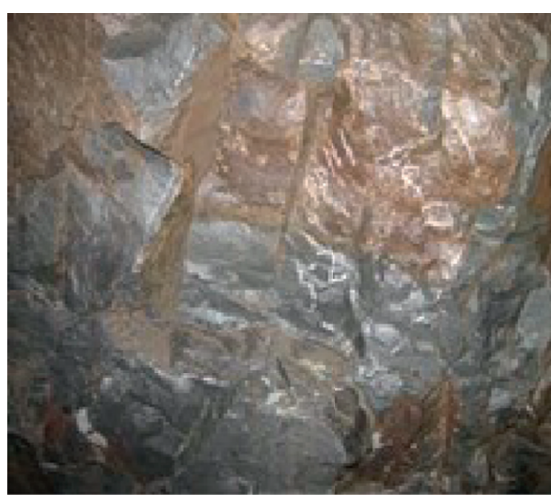

(c)

FIGURE 2: Field photographs of different types of rock masses: (a) CJB; (b) breccia lava; (c) cryptic basalt.

both slopes, the CJB is widely formed in the rock strata $\mathrm{P}_{2} \beta_{3}^{2}$ and $\mathrm{P}_{2} \beta_{3}^{3}$, and it is vital to investigate the rock masses at the foundation surface. In view of the adverse geological conditions in the Baihetan dam foundation, during the construction, the excavation stability must be taken into consideration. Figure 3 shows the layout of the field testing positions at the dam foundation, it illustrates that cryptic basalt, breccia lava, and CJB are distributed in different elevations, and several testing points are arranged at suitable positions. In practical engineering, at least one group and three points should be arranged in each group for different lithology, different strata, and different parts. Generally speaking, no less than five groups (a total of 15 points) should be appropriate, to fully reflect the situation of different lithologies with different integrity degrees. In this paper, the test of 30 group CJB rigid pressure plates on the left bank foundation of the Baihetan hydropower station is taken as an example.

As for the excavation process, the excavation of the slope at the abutment of the left bank dam foundation began in September 2013 at the elevation of $834.0 \mathrm{~m}$, and the anchor cable construction of the foundation surface above the elevation of the dam foundation was completed in November 2016. The excavation of the slope at the abutment area of the right bank foundation began in October 2014 at the elevation of $834.0 \mathrm{~m}$, and the excavation of the right bank foundation reached the elevation of $600 \mathrm{~m}$ in September 2016. Figure 4 shows the sketch of dam foundation excavation, and the dynamic loading is applied upon the protecting zone. According to the existing research achievements, the thickness of the protecting zone is confirmed associated with the geometry of blasting-induced damage zone, and the damage zone is defined as the rock region where has been influenced by the blast loading excavation [38]. The thickness of dam foundation protecting zone of some constructed large-scale projects is listed in Figure 4 [39-42]. Therefore, based on the comprehensive comparison, the dam foundation of the riverbed began to be excavated by reserving a $5 \mathrm{~m}$ protective layer in October 2016. The protective layer of the riverbed was fully excavated in January 2017, and the excavation was completed by March 10. In the excavation process, the noncolumnar jointed rock mass is excavated according to a ladder section per $10 \mathrm{~m}$. In the excavation of dam foundation, the phenomenon of 


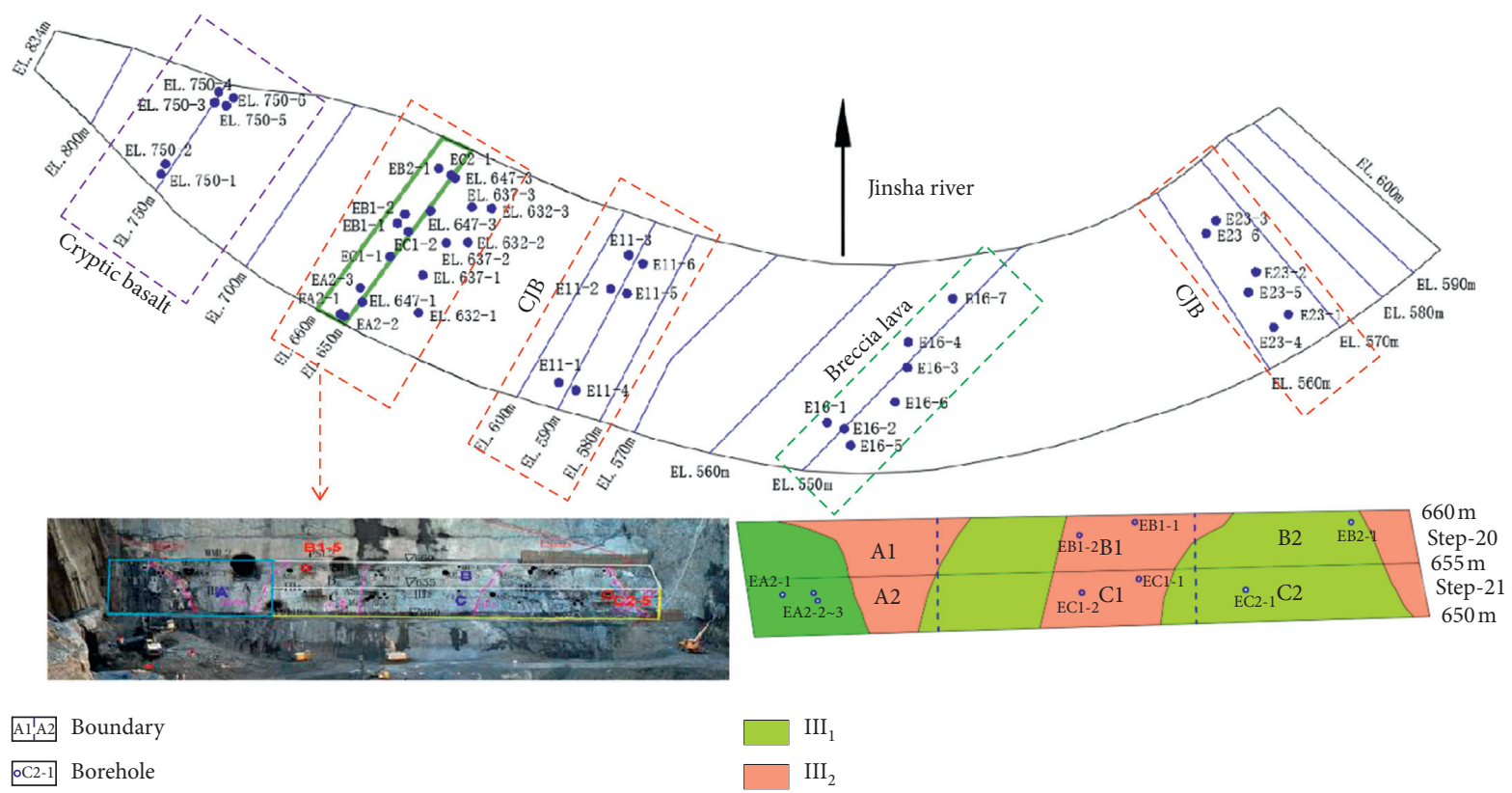

Figure 3: Layout of field testing positions at the dam foundation [18].

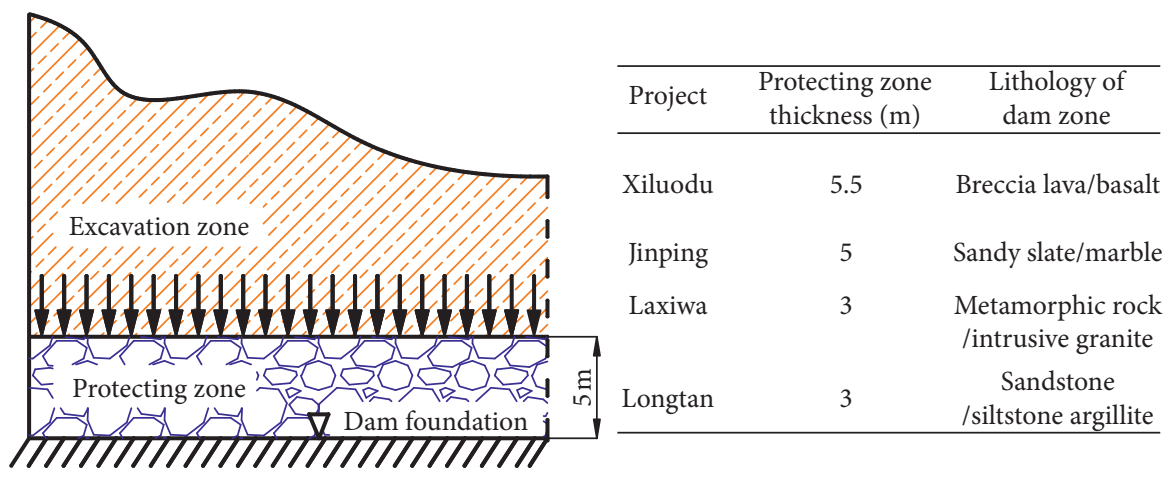

FIgURE 4: Sketch of dam foundation excavation.

unloading relaxation and fracture of column-jointed basalt was relatively obvious, so the excavation of column-jointed basalt rock mass was carried out according to a ladder section every $5 \mathrm{~m}$.

\section{In Situ Experiment of Deformation Tests and Acoustic Tests on Rock Masses}

3.1. Rigid Bearing Plate Tests. To carry out the in situ experiment, 43 groups of rigid bearing plates were set on the foundation surface of the Baihetan hydropower station. 30 of them were carried out on columnar jointed basalt and 13 on noncolumnar jointed rock masses. Figure 5 illustrates the field plate bearing tests on the CJB, and they contain the plate bearing test equipment installation (Figure 5(a)) and the deformation image of CJB (Figure 5(b)). The pressuredeformation curves of the rigid bearing plate tests are shown in Figure 5(c), and the elastic modulus can be calculated by the tangential modulus of the linear loading curves.

Four dial indicators on the rigid bearing plate monitor the deformation value of rock masses, and it includes the total deformation $W_{0}$ and elastic deformation $W_{e}$. The relationship between total deformation and elastic modulus can be expressed by

$$
E=\frac{\pi}{4} \times \frac{\left(1-\mu^{2} P D\right)}{W},
$$

where $E$ is the elastic or deformation modulus of rock masses, and $E_{0}$ is calculated by substituting the total deformation $W_{0}$ into the equation; $E_{e}$ is calculated by elastic deformation $W_{e}$ into the equation; $W$ is the surface deformation value of rock masses, and it refers to the total deformation $W_{0}$ or elastic deformation $W_{e} ; P$ is the pressure of per unit area of the bearing surface; $D$ is the diameter of rigid bearing plate; $\mu$ is Poisson's ratio of rock mass.

3.2. Acoustic Tests. At the distance of $15 \mathrm{~cm}$ outside the test surface of each rigid bearing plate, four acoustic test holes with a diameter of $50 \mathrm{~mm}$ and a depth of $250 \mathrm{~cm}$ were made with a pneumatic drill. During the test, a dual-receiver acoustic wave probe was put into the hole, and a transducer 


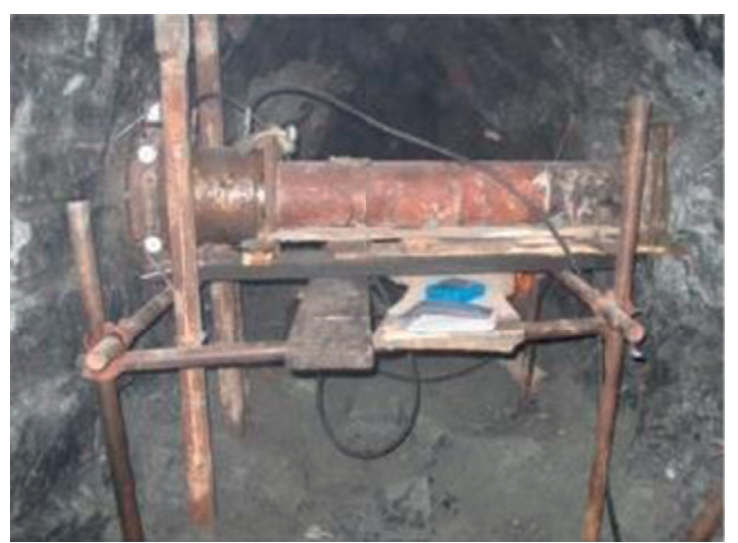

(a)

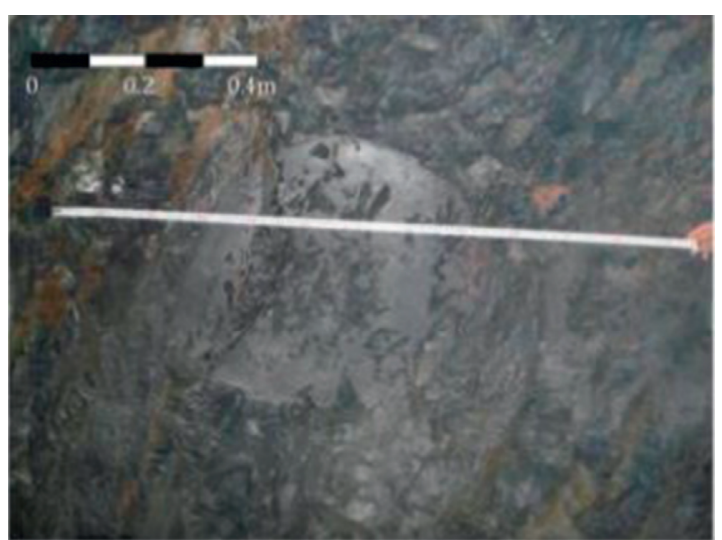

(b)

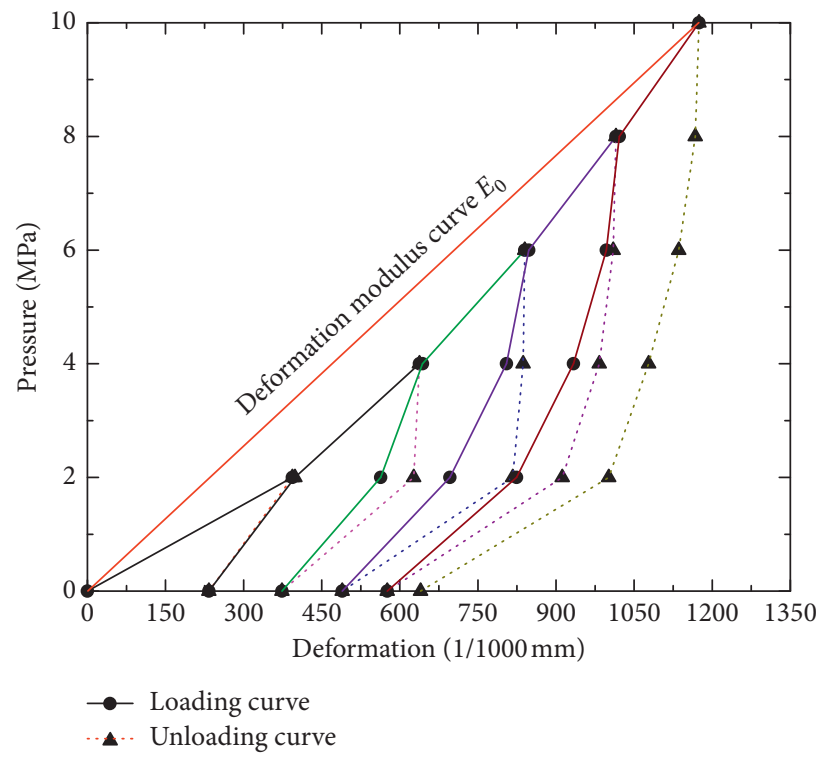

(c)

FIGURE 5: In situ rigid bearing plate tests on columnar jointed basalts (CJB): (a) bearing plate test equipment installation; (b) deformation of columnar basalts [16]; (c) pressure-deformation curves of rigid bearing plate tests.

was used to transmit the acoustic wave. Two transducers receive the acoustic wave, and the time difference between the two receiving transducers was monitored. The distance between the two receiving transducers divided by the time difference is the acoustic velocity of the rock mass of the pore wall where the receiving transducer is located. The measuring point distance $L=20 \mathrm{~cm}$ was measured between two acceptors. By observing and analyzing the propagation velocity of acoustic wave in the pore wall and its relative changes, the properties, structural characteristics, and relevant mechanical parameters of the medium were understood and the integrity of the rock mass was evaluated. The acoustic holes at each variable mode point were uniformly numbered, and the layout of the holes is shown in Figure 6.

When acoustic waves from different measuring points were monitored from the original acoustic record and travel to the two receiving transducers, the distance between the two receiving transducers was divided by the time difference, and then the acoustic velocity of the pore wall rock mass in this section can be obtained. The formulas are as follows:

$$
\begin{aligned}
& \Delta t=\left|t_{1}-t_{2}\right|, \\
& v_{p}=\frac{L}{\Delta t} \times 10^{6},
\end{aligned}
$$

where $t_{1}$ and $t_{2}$ are the arriving time to two receiving transducers of the same excitation signal, respectively; $\Delta t$ is the time difference; $L$ is the distance between two receiving transducers, and $L=0.2 \mathrm{~m}$, which is a fixed value; $v_{p}$ is the speed of the acoustic wave.

\subsection{Experimental Results of Rigid Bearing Plate and Acoustic} Tests. According to the results of rigid bearing plate and acoustic tests, the deformation modulus, elastic modulus, and the acoustic velocity were monitored, as listed in Table 1 . Besides, the acoustic waves propagate in different types of 


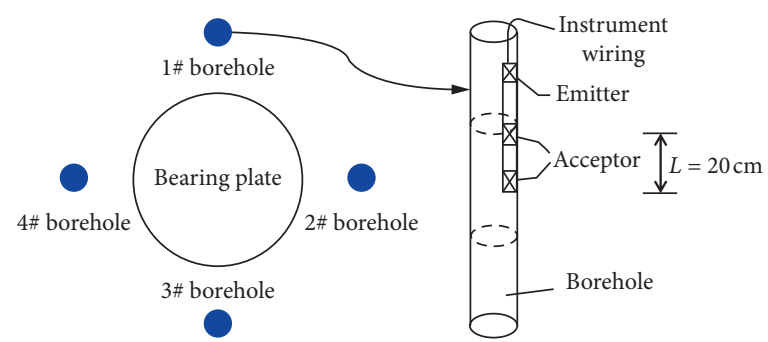

Figure 6: Layout of acoustic tests of borehole rock masses.

rock masses, the propagation velocity could be reduced to a vary degree, thus defining the attenuation rate $\eta$, to estimate the quality of rock masses, and it could be expressed by the following formula:

$$
\eta=1-\frac{v_{w}}{v_{0}}
$$

where $v_{0}$ is the incident velocity of acoustic wave and $v_{w}$ is the transit velocity of acoustic wave in the rock masses. Normally, when $\eta$ is less than $10 \%$, it is considered that the excavation has little or no influence on the rock masses; when the value of $\eta$ is between $10 \%$ and $15 \%$, the rock masses are considered slightly affected by the excavation; when $\eta$ is larger than $15 \%$, it is believed that the excavation has influence on the rock mass quality.

In Table 1, there is a great dispersion of the data obtained from field experiments, which indicates that the mechanical behaviors of CJB are significantly different. According to the data in Table 1, the diagram of elastic modulus and deformation modulus varying with elevation is depicted and shown in Figure 7. Figure 7(a) shows the data points' distribution of elastic modulus and deformation modulus in different elevation. It illustrates that the mechanical behaviors of CJB are different even in the same elevation. Figure 7(b) shows the bar graph, which represents the mean value and data standard deviation of elastic modulus and deformation modulus of CJB in the same elevation. From the figure, it indicates that the mechanical property differences in low elevation are larger than those in high elevation.

The elevation from $650 \mathrm{~m}$ to $660 \mathrm{~m}$ is the region of columnar jointed basalts, thus conducting further analysis in this area. From Figure 3, it can be seen that there are nine testing points in the area of $\mathrm{A} 2, \mathrm{~B} 1, \mathrm{~B} 2, \mathrm{C} 1$, and $\mathrm{C} 2$ : three points are in $\mathrm{A} 2$ area, two points are in area $\mathrm{B} 1$, one point is in area $\mathrm{B} 2$, two points are in area $\mathrm{C} 1$, and one point is in area $\mathrm{C} 2$. In the upstream of the test area, the intraformational faulted belt $\mathrm{LS}_{3319}$ was observed in the area of A1 and A2, the occurrence is $\mathrm{N} 10^{\circ} \mathrm{E}, \mathrm{SE} \angle 25^{\circ}$, and the bandwidth is $5 \sim 15 \mathrm{~cm}$, as shown in Figure 1. In addition to EA2-1 and EA2-2 points located in the footwall of $\mathrm{LS}_{3319}$, the other seven points were located in the upper wall of $\mathrm{LS}_{3319}$. Under its influence, the deformation modulus values of EA2-1 and EA2-2 points are $9.8 \mathrm{GPa}$ and $9.1 \mathrm{GPa}$, respectively, with an average of 9.5 GPa. The deformation modulus values of the remaining seven points ranged from $1.0 \mathrm{GPa}$ to $4.3 \mathrm{GPa}$, with an average of $2.8 \mathrm{GPa}$. During the process of dam foundation excavation, if dislocation interfaces are distributed in the protecting zone, the rock masses could be easily affected. The rock mass relaxation phenomenon in the upper wall of the dislocation interfaces is generally more serious than those in the footwall. Therefore, in this area, the intraformational faulted belt $\mathrm{LS}_{3319}$ indeed has great effects on the rock mass deformation modulus.

The deformation modulus values of the three points in the area $\mathrm{A}$ are the highest, which are significantly different from each other due to the influence of the rock structure. The deformation modulus values in $\mathrm{B}$ area are minimum, whose values are from $1.7 \mathrm{GPa}$ to $3.17 \mathrm{GPa}$. The deformation modulus value in $\mathrm{C}$ area is from $2.9 \mathrm{GPa}$ to $4.0 \mathrm{GPa}$, which corresponds to the real situation. Meanwhile, combined with the data in Table 1, it can be seen that the acoustic velocity in the area of CJB ranges from $3278 \mathrm{~m} / \mathrm{s}$ to $5125 \mathrm{~m} / \mathrm{s}$, with an average of $4207.2 \mathrm{~m} / \mathrm{s}$. The acoustic velocity attenuation rate of $\eta$ in CJB is within 0 and $26.9 \%$, and the proportion of $\eta$ less than $10 \%$ is $43.3 \%$; between $10 \%$ and $15 \%$ is $13.3 \%$; and larger than $15 \%$ is $43.3 \%$. Therefore, the CJB is sensitive to the elevation changing.

Figure 8(a) shows the results of in situ tests of CJB at different stages. In 2015, nine groups of tests were conducted on CJB at the elevation of $650 \sim 660 \mathrm{~m}$. With the downward excavation of the dam foundation, nine groups of tests were added to CJB at the elevation of $630 \sim 650 \mathrm{~m}$ in 2016 . Finally, in 2017, six groups of tests were added to CJB at the elevation of $585 \sim 595 \mathrm{~m}$ and $563 \sim 570 \mathrm{~m}$, respectively, so that the number of left bank foundation testing points was increased to thirty. Compared with the fitting results using all testing data, the fitting curve in $2015(N=9)$ is located above it, and under the same acoustic velocity, the deformation modulus is larger. The curve in 2016 takes the acoustic velocity of $4.5 \mathrm{~km} / \mathrm{s}$ as the cutoff point, and when $v_{p}$ is less than $4.5 \mathrm{~km} /$ $\mathrm{s}$, the deformation modulus is larger, while it is smaller when $v_{p}$ is greater than $4.5 \mathrm{~km} / \mathrm{s}$. In 2017 , the curve takes the $\mathrm{P}$-wave velocity of $4.8 \mathrm{~km} / \mathrm{s}$ as the cutoff point, and when $v_{p}$ is less than $4.8 \mathrm{~km} / \mathrm{s}$, the deformation modulus is smaller, while it is larger when it is larger than $4.8 \mathrm{~km} / \mathrm{s}$. Considering that a small number of testing points will produce great uncertainty to the fitting result, the parameter selection of the foundation surface in the later stage should be determined according to the comparison relation with more number of testing points.

There are generally two forms of $E_{0}-v_{p}$ function, i.e., power function and exponential function, as shown in 
TABLe 1: Results of field tests at the left bank of the Baihetan hydropower station [43].

\begin{tabular}{|c|c|c|c|c|c|c|}
\hline Monitoring position & Elevation $(\mathrm{m})$ & Elastic modulus $E_{e}(\mathrm{GPa})$ & Deformation modulus $E_{0}(\mathrm{GPa})$ & $v_{0}(\mathrm{~m} / \mathrm{s})$ & $v_{0}(\mathrm{~m} / \mathrm{s})$ & $\eta(\%)$ \\
\hline EA2-1 & 653.0 & 15.2 & 9.8 & 4900 & 4350 & 11.2 \\
\hline EA2-2 & 651.5 & 15.1 & 9.1 & 4900 & 4541 & 7.3 \\
\hline EA2-3 & 653.0 & 7.1 & 4.3 & 4350 & 3685 & 15.3 \\
\hline EC1-1 & 651.2 & 5.6 & 3.5 & 4900 & 4147 & 15.4 \\
\hline EC1-2 & 651.4 & 5.0 & 2.9 & 4350 & 3742 & 14.0 \\
\hline EC2-1 & 651.3 & 6.2 & 3.5 & 4900 & 3781 & 22.8 \\
\hline EB1-1 & 656.2 & 2.4 & 1.4 & 4350 & 3492 & 19.7 \\
\hline EB1-2 & 656.2 & 1.8 & 1.0 & 4350 & 3278 & 24.6 \\
\hline EB2-1 & 656.5 & 6.9 & 3.2 & 4900 & 3620 & 26.1 \\
\hline EL.632-1 & 632.0 & 17.7 & 13.2 & 4900 & 4739 & 3.3 \\
\hline EL.632-2 & 632.0 & 13.2 & 8.7 & 4900 & 4659 & 4.9 \\
\hline EL.632-3 & 632.0 & 19.3 & 12.2 & 4900 & 4577 & 6.6 \\
\hline EL.637-1 & 637.0 & 6.0 & 4.4 & 4900 & 3580 & 26.9 \\
\hline EL.637-2 & 638.0 & 6.8 & 3.4 & 4900 & 4413 & 9.9 \\
\hline EL.637-3 & 636.0 & 13.1 & 8.2 & 4900 & 4332 & 11.6 \\
\hline EL.647-1 & 647.0 & 12.3 & 7.4 & 4900 & 4757 & 2.9 \\
\hline EL.647-2 & 646.0 & 17.0 & 9.8 & 4900 & 4440 & 9.4 \\
\hline EL.647-3 & 648.0 & 9.5 & 5.4 & 4900 & 3937 & 19.7 \\
\hline E11-1 & 592.0 & 11.4 & 8.5 & 4900 & 4833 & 1.4 \\
\hline E11-2 & 592.0 & 6.4 & 4.4 & 4900 & 4464 & 8.9 \\
\hline E11-3 & 592.0 & 7.1 & 4.5 & 4900 & 4375 & 10.7 \\
\hline E11-4 & 587.0 & 29.7 & 23.7 & 4900 & 5125 & 0 \\
\hline E11-5 & 587.0 & 12.6 & 9.8 & 4900 & 4802 & 2.0 \\
\hline E11-6 & 587.0 & 6.8 & 5.1 & 4900 & 4569 & 6.8 \\
\hline
\end{tabular}

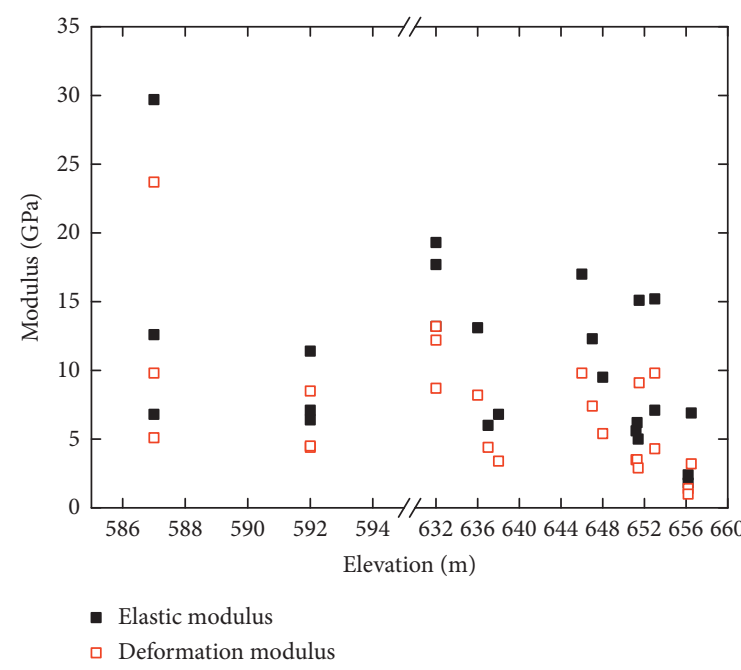

(a)

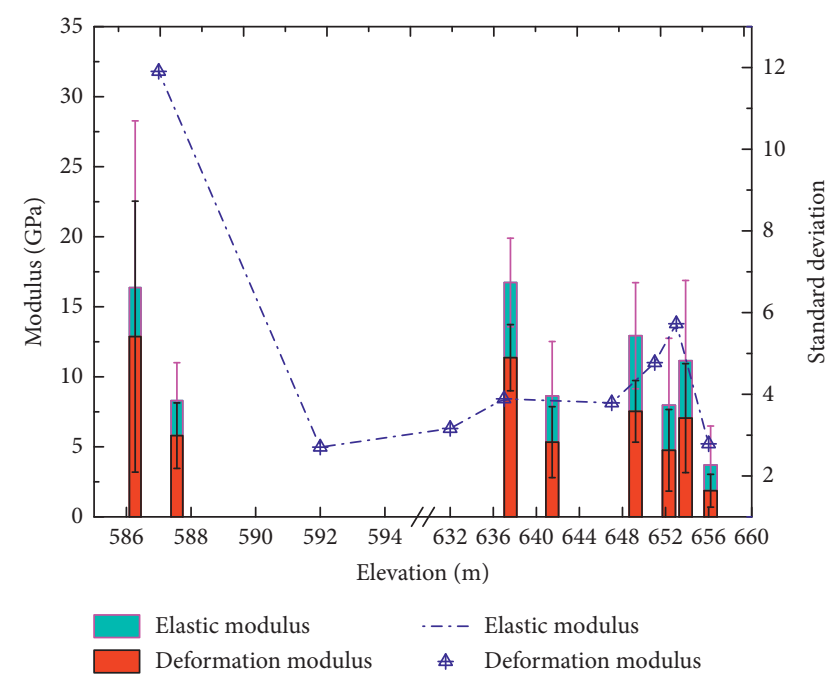

(b)

FIGURE 7: Diagram of Elastic modulus and deformation modulus varying with elevation: (a) data points' distribution of elastic modulus and deformation modulus in different elevation; (b) mean value and standard deviation of elastic modulus and deformation modulus.

Figure $8(\mathrm{~b})$. The power function can be expressed by $E_{0}=0.01398 e^{1.40806 v_{p}}$, and the exponential function can be fitted by $E_{0}=0.000674 v_{p}{ }^{6.244}$. When $v_{p}$ is lower than $4.0 \mathrm{~km} /$ $\mathrm{s}$ or higher than $4.75 \mathrm{~km} / \mathrm{s}$, the exponential function is higher than that of the power function. When $v_{p}$ is between $4.0 \mathrm{~km} /$ $\mathrm{s}$ and $4.75 \mathrm{~km} / \mathrm{s}$, the power function is slightly higher than that of the exponential function, and there is almost no difference between them. In addition, when the same data were used to establish the power function and exponential function, the difference was within $3 \%$.

The different mechanical properties at different elevation of CJB have been discussed above, and the fitting functions of deformation modulus and acoustic velocity are proposed, which are valuable for the determining parameters of CJB by rigid bearing plate tests or acoustic tests. Therefore, in the next section, different types of CJB with different joint angles 


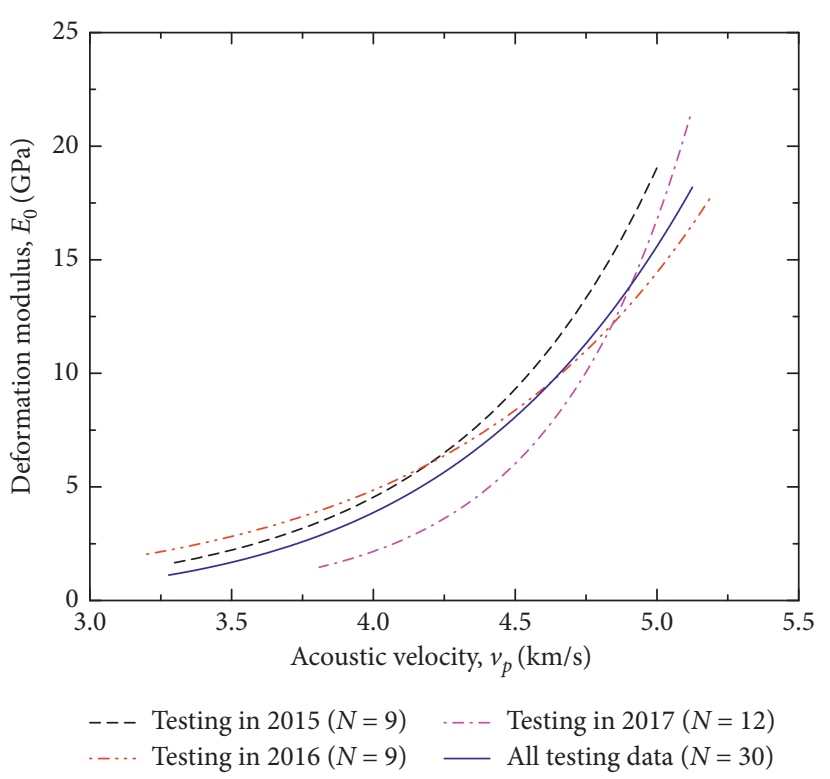

(a)

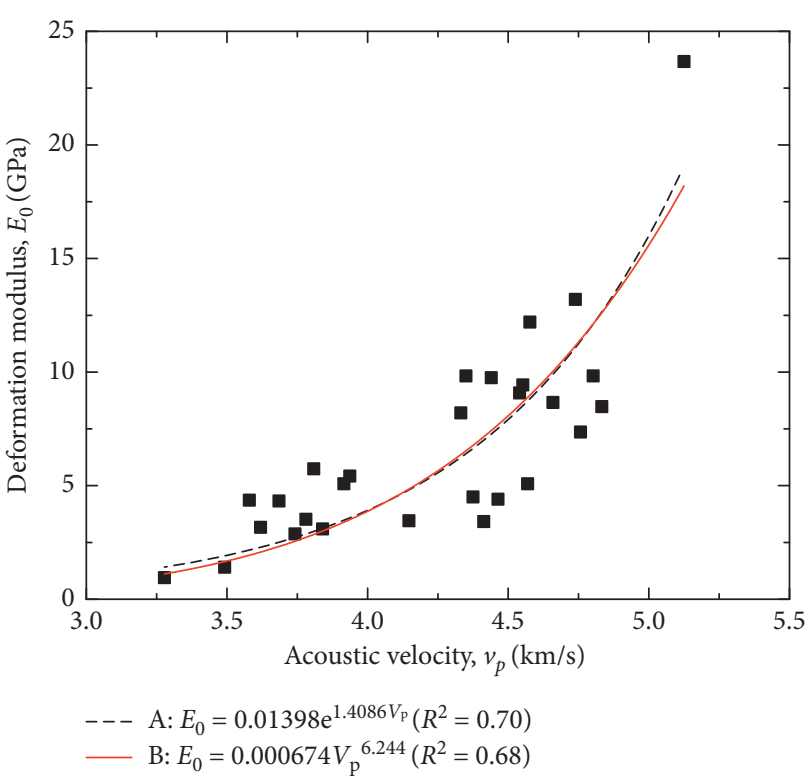

(b)

Figure 8: $E_{0^{-}} v_{p}$ curves of CJB at the left bank in different periods and fitting functions. (a) $E_{0^{-}} v_{p}$ curves of CJB in different periods and (b) different fitting functions for $E_{0}-v_{p}$.

and thickness of weak intercalations are further discussed by numerical simulation methods.

\section{Numerical Simulation}

4.1. Model Establishing and Property Assignment. In this section, the numerical simulation software is employed to deal with the problems of columnar jointed basalt, and several numerical models were established with different angles and widths of joints in rock mass, to analyze the strength and failure modes of irregular CJB. As Figure 9 shows, the cubical CJB samples with $50 \mathrm{~mm}$ width and $50 \mathrm{~mm}$ height were modeled, and there are seven angles of the joint, i.e., $\beta=0^{\circ}, 15^{\circ}, 30^{\circ}, 45^{\circ}, 60^{\circ}, 75^{\circ}$, and $90^{\circ}$. Besides, different thickness of weak plane in CJB, such as $1.25 \mathrm{~mm}$, $2.5 \mathrm{~mm}, 3.75 \mathrm{~mm}, 5 \mathrm{~mm}, 6.25 \mathrm{~mm}$, and $10 \mathrm{~mm}$, was also built under the most unfavorable angle of joints in CJB, as shown in Figure 9.

The constitutive model named ubiquitous-joint model can be adopted to simulate the presence of an orientation of the weak plane in Mohr-Coulomb material where shear failure can be simulated. The compressive strength of the rock mass is a function of the material and joint properties, formed by the direction of the compressive stress and its projection onto the plane of weakness. Therefore, the rock mass of CJB is assigned by the Mohr-Coulomb, and the joint in CJB is assigned ubiquitous-joint properties. The properties adopted in this paper for rock mass and joints are listed in Table 2.

Based on the analysis results of numerical simulation of uniaxial compression, the adverse joint angle and thickness are confirmed; thus, the excavation stability of the drainage tunnel can be further discussed. The materials properties are assigned as the parameters listed in Table 2. As shown in Figure 10, the dimension of the model is $50 \mathrm{~mm}$ in length $(L), 50$ in width $(W)$, and $25 \mathrm{~m}$ in depth $(h)$. According to the principle of tunnel symmetry, the tunnel is set as a quarter section drainage tunnel, and the diameter of the tunnel is $4 \mathrm{~m}(D)$. The width of joints in CJB is $10 \mathrm{~cm}$, and the excavation length of each step is $5 \mathrm{~m}$.

4.2. Numerical Simulation Results. Figure 11 shows the stress-strain curves of CJB with different joint angles, it illustrates that different joint CJB with different joint angles performs variety of mechanical properties. CJB with a joint angle of $0^{\circ}$ performs the largest compression strength, and the angle of $30^{\circ} \sim 60^{\circ}$ presents weak antipressure ability, because the shear slipping force in CJB with $0^{\circ}$ joint is the smallest, while the slipping force in CJB with angles of $30^{\circ} \sim 60^{\circ}$ is more remarkable, and they are more likely to make CJB turn into deformation and be damaged. Moreover, CJB, with joint angle of $0^{\circ}$ or $90^{\circ}$, bears the parallel or vertical direction loading stress, and there are few slipping forces in these cases; thus, they are favorable for CJB. Most of the rock specimens perform the largest stress strength at the strain of $0.8 \%$, except for the CJB with the joint angle of $90^{\circ}$, whose value is $0.6 \%$ when it represents the largest stress strength.

Figure 12 shows the cutting plane contour of the plastically deforming area in CJB with different joint angles calculated by FLAC ${ }^{3 \mathrm{D}}$, it indicates that the joint angle from $15^{\circ}$ to $75^{\circ}$ shows a complicated stress state, which tends to be easily damaged. When the joint angle is $0^{\circ}$ or $90^{\circ}$, the core of rock sample is mostly bearing compression and lack of shear slipping, and they are bearing stress states in the compression process. However, with the increase of joint angle, the element in CJB bears different types of stress, especially in the joint angle of $45^{\circ}$ to $75^{\circ}$.

Figure 13 shows the stress-strain curves of CJB with different joint thickness, and the values of joint thickness are 

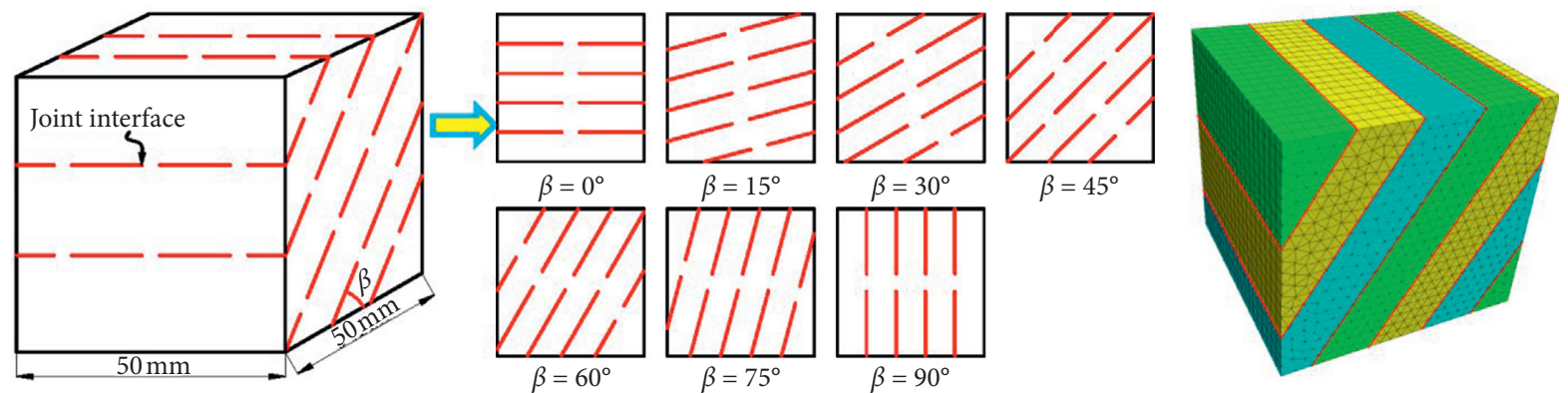

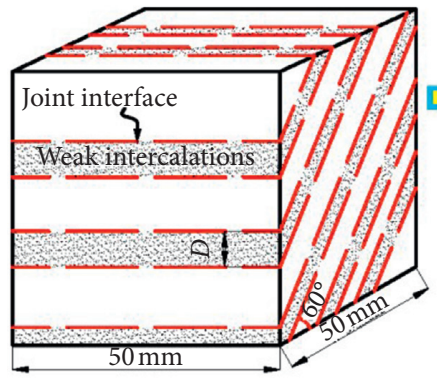

(a)

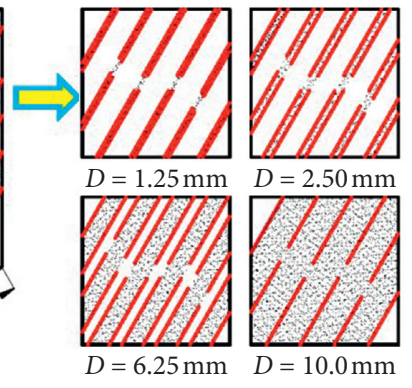

(b)
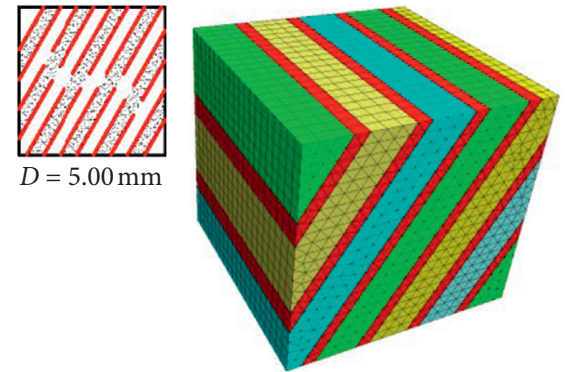

(c)

FIgURE 9: Different joint angles and thickness of weakness in CJB employed in numerical simulation of uniaxial compression.

TABLE 2: Mohr-Coulomb and ubiquitous-joint properties used in numerical simulation.

\begin{tabular}{lccccc}
\hline Material & Bulk modulus $(\mathrm{GPa})$ & Cohesion $(\mathrm{kPa})$ & Dilation $\left(^{\circ}\right)$ & Friction angle $\left({ }^{\circ}\right)$ & Tension limit $(\mathrm{kPa})$ \\
\hline CJB & 10 & 7000 & 0 & 40 & 1000 \\
Joint & - & 300 & 0 & 29 & 50 \\
\hline
\end{tabular}

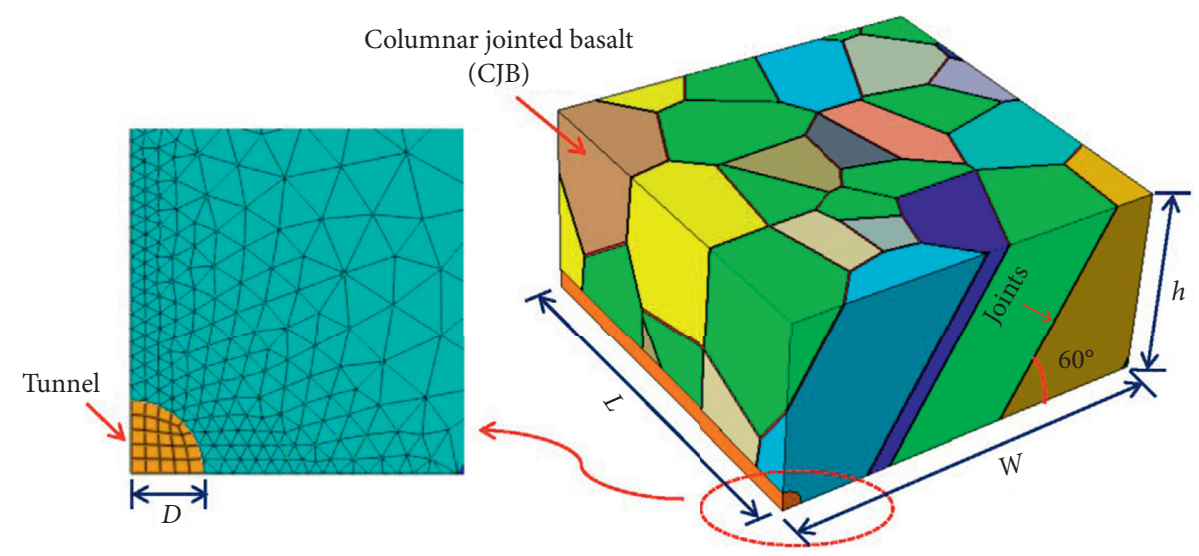

FIgURE 10: Numerical simulation models of tunneling in CJB.

$0 \mathrm{~mm}, 1.25 \mathrm{~mm}, 2.5 \mathrm{~mm}, 3.75 \mathrm{~mm}, 5 \mathrm{~mm}, 6.25 \mathrm{~mm}$, and $10 \mathrm{~mm}$, respectively. With the increase of thickness of weak intercalation, the stress strength gradually decreases and then there was a tiny increase, which indicates that the small material property difference is helpful for the compressive strength of rock masses. When the thickness of weak intercalation increases from $0 \mathrm{~mm}$, the stress strength decreases sharply, because the mechanical properties of weak intercalation are in poor quality, and it has a great influence on the overall strength of rock mass. When the thickness of weak intercalation increases to a certain value $(3.75 \mathrm{~mm})$, the stress strength of CJB appears a tiny increase, because the rock specimen gradually becomes intact, and it is advantageous for the stress strength of CJB.

Figure 14 shows the cutting plane contour of the plastically deforming area in CJB with different joint thickness calculated by FLAC ${ }^{3 \mathrm{D}}$, and it suggests that the stress state in each thickness of joint in CJB is variety during the compression process. By comparison, the thickness of $6.25 \mathrm{~mm}$ and $10 \mathrm{~mm}$ is in few stress state, which indicates that the 


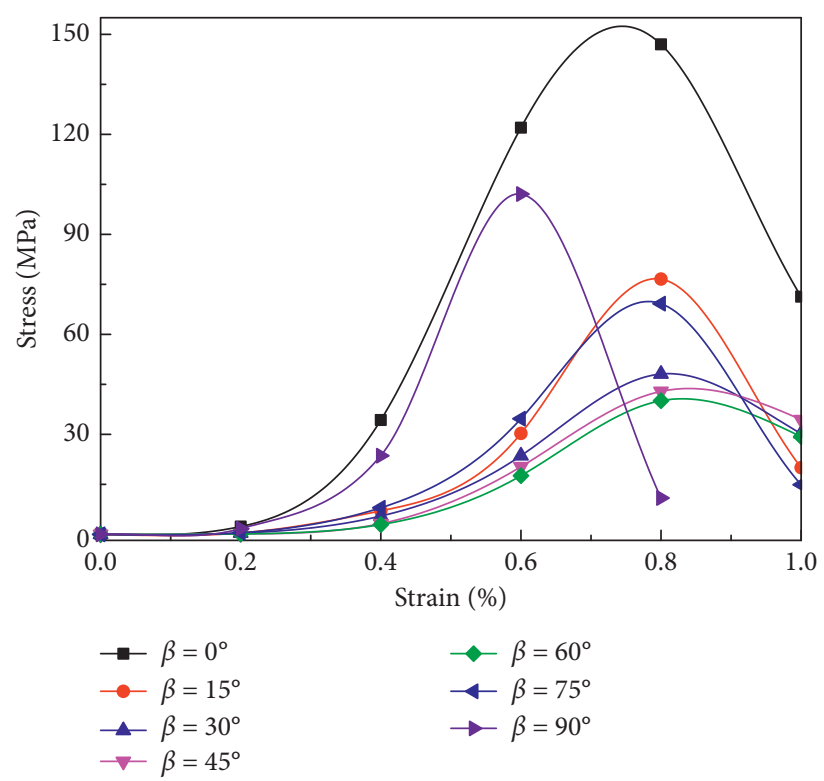

Figure 11: Stress-strain curves of CJB with different joint angles.
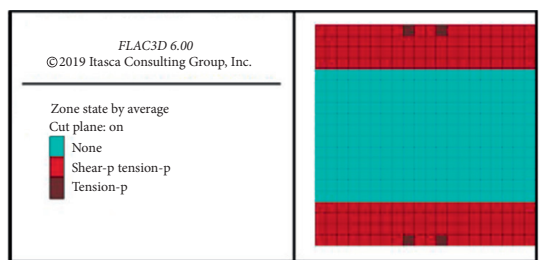

$\beta=0^{\circ}$
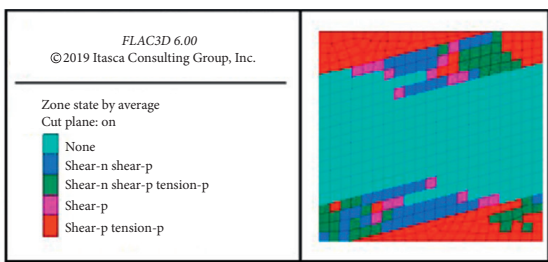

$\beta=15^{\circ}$
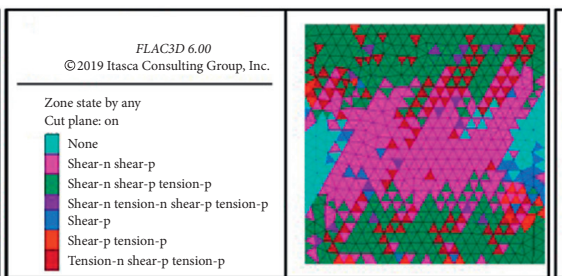

$\beta=60^{\circ}$

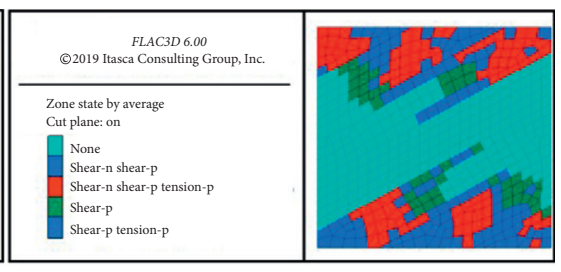

$\beta=30^{\circ}$
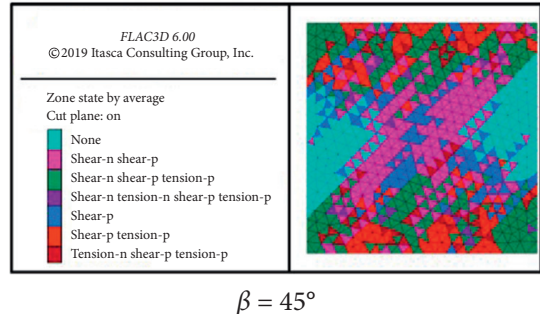

$\beta=45^{\circ}$

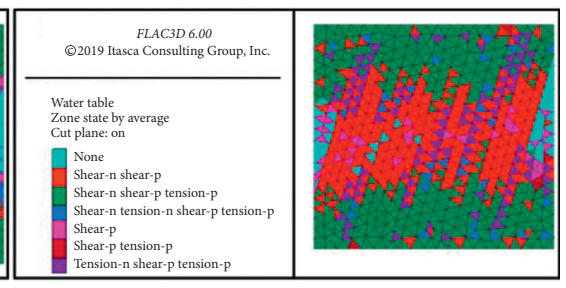

$\beta=75^{\circ}$

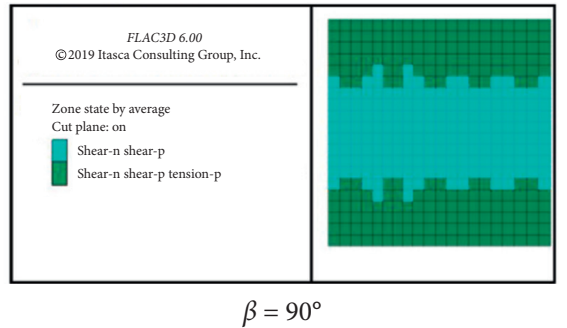

FIGURE 12: The cutting plane contour of plastically deforming area in CJB with different joint angles calculated by FLAC ${ }^{3 \mathrm{D}}$

stress strength in these cases is higher than others, and this result is corresponding to the stress-strain curve depicted before.

Figure 15 shows the curves of maximum displacement in each excavation step in CJB and intact rock masses. It illustrates that the CJB is adverse geological conditions for tunneling, as it is easily damaged along the directions of rock joints in them. In Figure 15(a), to compare the different mechanical properties of CJB, tunneling in intact rock masses is modeled as well, and the maximum displacement of at the top of tunnel is monitored. The figure suggests that the maximum displacement in CJB is larger than in intact rock masses. Following the excavation step, the vault crown settlement gradually increases and then tends to be stable. Within the excavation length of $20 \mathrm{~m}$, the displacement variation value is in high level. The reasons for this are mainly the initial moment of tunneling is unstable, ground disturbance is remarkable, besides, the number of joints in 


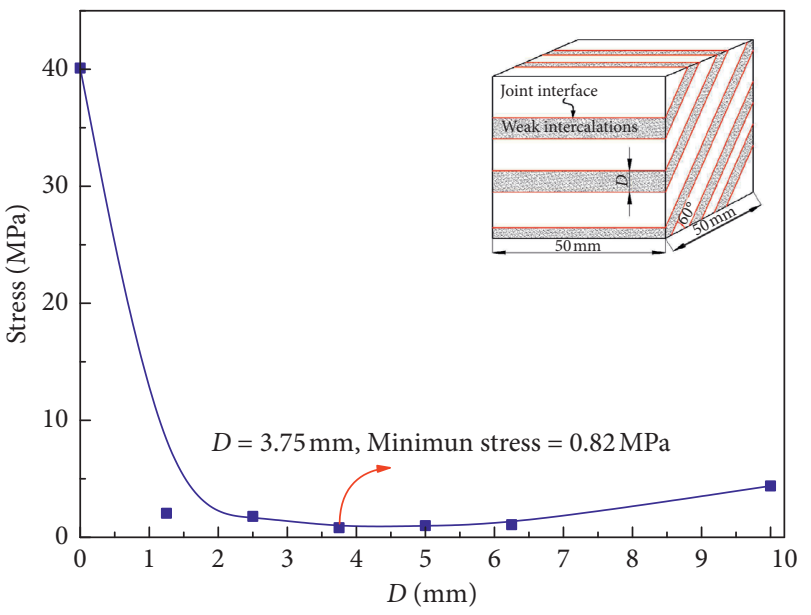

FIGURE 13: Stress-strain curve of CJB with different joint thickness.

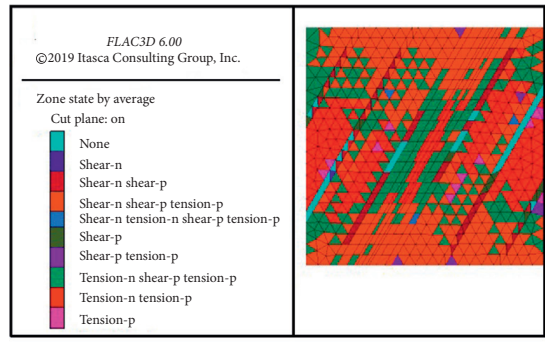

$D=1.25 \mathrm{~mm}$

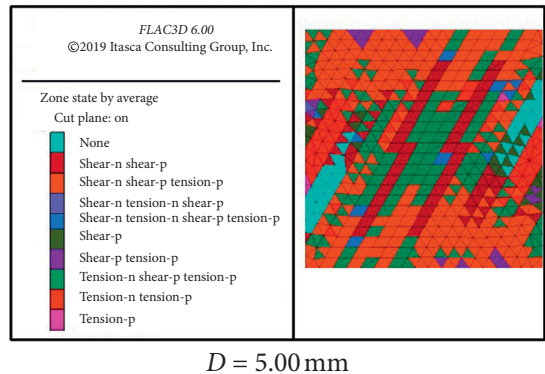

FIgURE 14: The view cutting contour of plastically deforming area in CJB with different joint thickness calculated by FLAC ${ }^{3 \mathrm{D}}$

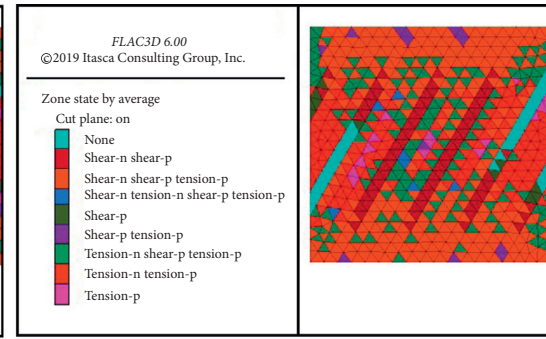

$D=2.50 \mathrm{~mm}$

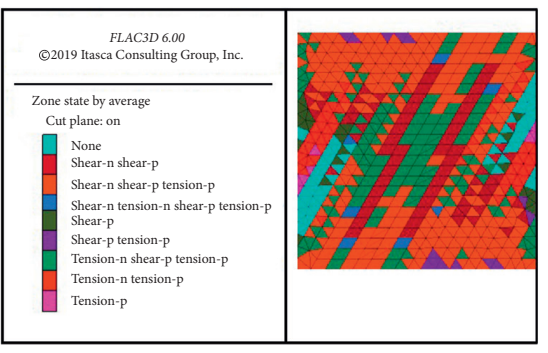

$D=6.25 \mathrm{~mm}$

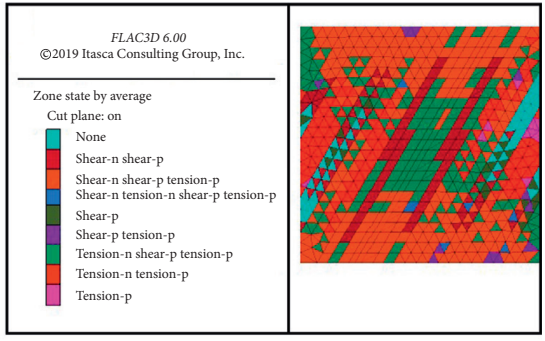

$D=3.75 \mathrm{~mm}$

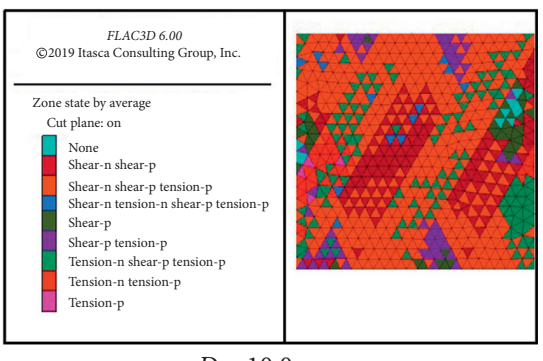

$D=10.0 \mathrm{~mm}$

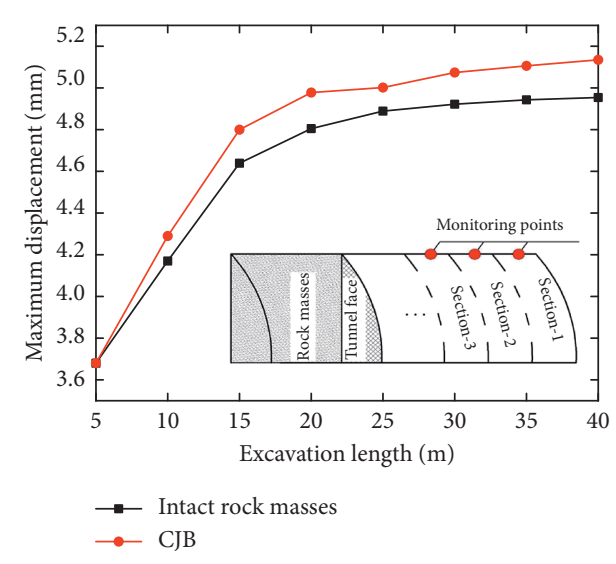

(a)

FIGURE 14: The view cutting contour of plastically deforming area in C)B with different joint thickness calculated by FLAC

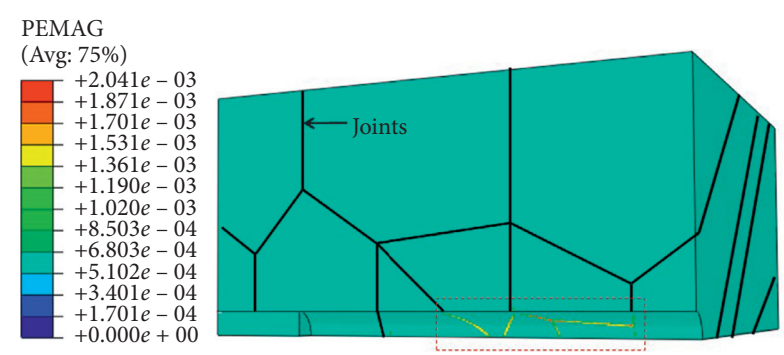

(b)

FIGURE 15: Numerical simulation results of tunneling in CJB: (a) curves of maximum displacement in each excavation step in CJB and intact rock masses; (b) the contour of plastic strain magnitude (PEMAG) tunneling in CJB. 
CJB is larger than the later excavation zone, as shown in Figure 15(b), which easily causes rock slipping and instable failure.

\section{Conclusion}

Detailed in situ tests of columnar jointed basalts (CJBs) in the Baihetan hydropower station dam foundation have been conducted, and the field tests mainly include rigid bearing plate tests and acoustic tests. Based on the monitoring data from the tests, the relationship between deformation modulus and acoustic velocity was expressed by function expressions. To further investigate the mechanical behaviors of CJB with different joint angles and widths, the numerical simulation models were then established, and the material parameters of rock masses were assigned related to the data from field tests. According to the results of numerical simulation, the most adverse joint angle and width were proposed. Finally, adopting the most unfavorable joint angle and width to model the tunneling process in $\mathrm{CJB}$, it suggests that it is easily damaged along the directions of rock joints in CJB when constructing in tunnels. The conclusions are as follows:

(1) The discreteness of data monitored from the field tests is large, and the mechanical behaviors of CJB are obviously different from those in the same elevation, the mechanical property differences in low elevation are larger than those in high elevation of Baihetan hydropower station, which means that the joints state and distribution patterns in CJB have great influence on the mechanical behaviors of rock masses.

(2) The power function $E_{0}=0.01398 e^{1.40806 v_{p}}$ and exponential function $E_{0}=0.000674 v_{p}{ }^{6.244}$ can be well employed to express the function relationship between deformation modulus and acoustic velocity, which are valuable for the determining parameters of CJB by rigid bearing plate tests or acoustic tests.

(3) The CJB with different joint angles performs distinct mechanical properties, and the angles of $30^{\circ} \sim 60^{\circ}$ present weak antipressure abilities, because the shear slipping force in CJB with $0^{\circ}$ joint is the smallest, while is more remarkable in CJB with the angle of $30^{\circ} \sim 60^{\circ}$, which may occur instable failure.

(4) When the thickness of weak intercalation increases from $0 \mathrm{~mm}$, the stress strength decreases sharply, because the mechanical properties of weak intercalation are in poor quality, and it has a great influence on the overall strength of rock masses. When the thickness of weak intercalation increases to a certain value, the stress strength of CJB appears a tiny increase, because the rock specimen gradually becomes intact, and it is advantageous for the stress strength of CJB.

(5) When tunneling in columnar jointed basalts, it is easily damaged along the directions of rock joints; thus, in the related constructions, it is significantly important to take some measures to prevent the damage of the joints.

\section{Data Availability}

The data used to support the findings of this study are included within the article and also available from the corresponding author upon request.

\section{Conflicts of Interest}

The authors declare that there are no conflicts of interest regarding the publication of this paper.

\section{Acknowledgments}

The authors are grateful for the financial supports from the Department of Communications of Zhejiang Province Science Foundation of China (grant no. 2020046) and the State Key Program of the National Natural Science of China (grant no. 52038008).

\section{References}

[1] Y. Xia, C. Zhang, H. Zhou et al., "Structural characteristics of columnar jointed basalt in drainage tunnel of Baihetan hydropower station and its influence on the behavior of P-wave anisotropy," Engineering Geology, vol. 264, Article ID 105304, 2020.

[2] P. Lin, J. Shi, P. Wei, Q. Fan, and Z. Wang, "Shallow unloading deformation analysis on Baihetan super-high arch dam foundation," Bulletin of Engineering Geology and the Environment, vol. 78, no. 8, pp. 5551-5568, 2019.

[3] Q.-X. Meng, H.-L. Wang, W.-Y. Xu, and Y.-L. Chen, "Numerical homogenization study on the effects of columnar jointed structure on the mechanical properties of rock mass," International Journal of Rock Mechanics and Mining Sciences, vol. 124, Article ID 104127, 2019.

[4] G. Feng, X. C. Wang, M. Wang, and Y. Kang, "Experimental investigation of thermal cycling effect on fracture characteristics of granite in a geothermal-energy reservoir," Engineering Fracture Mechanics, vol. 235, Article ID 107180, 2020.

[5] X. Wang, C. Liu, S. Chen, L. Chen, K. Li, and N. Liu, "Impact of coal sector's de-capacity policy on coal price," Applied Energy, vol. 265, Article ID 114802, 2020.

[6] Y. H. Hatzor, X.-T. Feng, S. Li, G. Yagoda-Biran, Q. Jiang, and $\mathrm{L}$. Hu, "Tunnel reinforcement in columnar jointed basalts: the role of rock mass anisotropy," Tunnelling and Underground Space Technology, vol. 46, pp. 1-11, 2015.

[7] H. Bao, K. Zhang, C. Yan, H. Lan, F. Wu, and H. Zheng, "Excavation damaged zone division and time-dependency deformation prediction: a case study of excavated rock mass at Xiaowan hydropower station," Engineering Geology, vol. 272, Article ID 105668, 2020.

[8] H. Ji, J. C. Zhang, W. Y. Xu et al., "Experimental investigation of the anisotropic mechanical properties of a columnar jointed rock mass: observations from laboratory-based physical modelling," Rock Mechanics and Rock Engineering, vol. 50, no. 7, pp. 1919-1931, 2017.

[9] N. Xu, J. Wu, F. Dai et al., "Comprehensive evaluation of the stability of the leftbank slope at the Baihetan hydropower station in southwest China," Bulletin of Engineering Geology and the Environment, no. 4, pp. 1-22, 2017. 
[10] Y.-X. Xiao, X.-T. Feng, B.-R. Chen, G.-L. Feng, Z.-B. Yao, and L.-X. Hu, "Excavation-induced microseismicity in the columnar jointed basalt of an underground hydropower station," International Journal of Rock Mechanics and Mining Sciences, vol. 97, pp. 99-109, 2017.

[11] F. Wu, J. Liu, T. Liu, H. Zhuang, and C. Yan, "A method for assessment of excavation damaged zone (EDZ) of a rock mass and its application to a dam foundation case," Engineering Geology, vol. 104, no. 3-4, pp. 254-262, 2009.

[12] Y. L. Bao and J. L. Wan, "The innovation on foundation excavation for Laxiwa double arch dam," Journal of Northwest Hydroelectric Power, vol. 22, no. 5, pp. 79-81, 2006, in Chinese.

[13] X. Shen, X. Niu, W. Lu et al., "Rock mass utilization for the foundation surfaces of high arch dams in medium or high geo-stress regions: a review," Bulletin of Engineering Geology and the Environment, vol. 76, no. 2, pp. 795-813, 2016.

[14] J. Cui, Q. Jiang, X. Feng et al., "Insights into statistical structural characteristics and deformation properties of columnar jointed basalts: field investigation in the Baihetan dam base, China," Bulletin of Engineering Geology and the Environment, vol. 77, no. 2, pp. 775-790, 2017.

[15] M. Espada, J. Muralha, J. V. Lemos et al., "Safety analysis of the left bank excavation slopes of baihetan arch dam foundation using a discrete element model," Rock Mechanics and Rock Engineering, vol. 51, no. 8, pp. 2597-2615, 2018.

[16] J. Wang, Y. Zhang, Z. Qin, S. Song, and P. Lin, "Analysis method of water inrush for tunnels with damaged waterresisting rock mass based on finite element method-smooth particle hydrodynamics coupling," Computers and Geotechnics, vol. 126, Article ID 103725, 2020.

[17] W. Han, G. Li, Z. Sun, H. Luan, C. Liu, and X. Wu, "Numerical investigation of a foundation pit supported by a composite soil nailing structure," Symmetry, vol. 12, no. 2, p. 252, 2020.

[18] Q. Fan, Z. Wang, J. Xu, M. Zhou, Q. Jiang, and G. Li, "Study on deformation and control measures of columnar jointed basalt for baihetan super-high arch dam foundation," Rock Mechanics and Rock Engineering, vol. 51, no. 8, pp. 2569-2595, 2017.

[19] B. Chen, S. Zhang, Y. Li, Z. Li, and H. Zhou, "Physical simulation study of crack propagation and instability information discrimination of rock-like materials with faults," Arabian Journal of Geosciences, vol. 13, no. 18, 2020.

[20] J. Chen, J. Zhao, S. Zhang, Y. Zhang, F. Yang, and M. Li, “An experimental and analytical research on the evolution of mining cracks in deep floor rock mass," Pure and Applied Geophysics, vol. 177, no. 11, p. 5325, 2020.

[21] J. Xu, A. Haque, W. Gong et al., "Experimental study on the bearing mechanisms of rock-socketed piles in soft rock based on micro X-ray CT analysis," Rock Mechanics and Rock Engineering, vol. 53, no. 8, pp. 3395-3416, 2020.

[22] H. Y. Pan, D. W. Yin, N. Jiang, and Z. G. Xia, "Crack initiation behaviors of granite specimens containing crossing-doubleflaws with different lengths under uniaxial loading," Advances in Civil Engineering, vol. 2020, Article ID 8871335, 13 pages, 2020.

[23] D. Liu, Z. Gu, R. Liang et al., "Impacts of pore-throat system on fractal characterization of tight sandstones," Geofluids, vol. 2020, Article ID 4941501, 17 pages, 2020.

[24] Q. Jiang, X.-T. Feng, Y. H. Hatzor, X.-J. Hao, and S.-J. Li, "Mechanical anisotropy of columnar jointed basalts: an example from the Baihetan hydropower station, China," Engineering Geology, vol. 175, pp. 35-45, 2014.
[25] C. Zhu, M. He, M. Karakus, X. Cui, and Z. Tao, "Investigating toppling failure mechanism of anti-dip layered slope due to excavation by physical modelling," Rock Mechanics and Rock Engineering, vol. 53, no. 11, p. 5029, 2020.

[26] J. Yang, J. Dai, C. Yao, S. Jiang, C. Zhou, and Q. Jiang, "Estimation of rock mass properties in excavation damage zones of rock slopes based on the Hoek-Brown criterion and acoustic testing," International Journal of Rock Mechanics and Mining Sciences, vol. 126, Article ID 104192, 2020.

[27] Q. Fan, X. Feng, W. Weng, Y. Fan, and Q. Jiang, "Unloading performances and stabilizing practices for columnar jointed basalt: a case study of Baihetan hydropower station," Journal of Rock Mechanics and Geotechnical Engineering, vol. 9, no. 6, pp. 1041-1053, 2017.

[28] D. Zhong, Y. Liu, L. Cheng, Q. Yang, and Y. Chen, "Study of unloading relaxation for excavation based on unbalanced force and its application in baihetan arch dam," Rock Mechanics and Rock Engineering, vol. 52, no. 6, p. 1819, 2018.

[29] D. Sow, C. Carvajal, P. Breul et al., "Modeling the spatial variability of the shear strength of discontinuities of rock masses: application to a dam rock mass," Engineering Geology, vol. 220, pp. 133-143, 2017.

[30] L. Yan, W. Xu, R. Wang, and Q. Meng, "Numerical simulation of the anisotropic properties of a columnar jointed rock mass under triaxial compression," Engineering Computations, vol. 35, no. 4, pp. 1788-1804, 2018.

[31] X. Wang, N. Wu, L. Hong, and Y. Yan, "Influence of joint angle on the instability failure characteristics and AE evolution law of underground caverns," European Journal of Environmental and Civil Engineering, 2020.

[32] C. Zhu, Z. G. Tao, S. Yang, and S. Zhao, "V shaped gully method for controlling rockfall of high-steep slope in China," Bulletin of Engineering Geology and the Environment, vol. 78, no. 4, pp. 2731-2747, 2019.

[33] C. Jia, W. Xu, S. Wang, R. Wang, and J. Yu, "Experimental analysis and modeling of the mechanical behavior of breccia lava in the dam foundation of the Baihetan hydropower project," Bulletin of Engineering Geology and the Environment, vol. 78, no. 4, p. 2681, 2018.

[34] A. Shi, Y. Wei, J. Wu, D. Ren, and M. Tang, "Study on the shear deformation of intralayer shear bands at the Baihetan hydropower station dam foundation," Bulletin of Engineering Geology and the Environment, vol. 79, no. 7, p. 3517, 2020.

[35] C. Jin, S. Li, and J. Liu, "Anisotropic mechanical behaviors of columnar jointed basalt under compression," Bulletin of Engineering Geology and the Environment, vol. 77, no. 1, pp. 317-330, 2016.

[36] M. Chen, S.-Q. Yang, P. G. Ranjith, and Y.-C. Zhang, "Cracking behavior of rock containing non-persistent joints with various joints inclinations," Theoretical and Applied Fracture Mechanics, vol. 109, Article ID 102701, 2020.

[37] C. Zhou, M. Karakus, C. Xu, and J. Shen, "A new damage model accounting the effect of joint orientation for the jointed rock mass," Arabian Journal of Geosciences, vol. 13, no. 7, p. 295, 2020.

[38] Y. Zhang, W. Lu, M. Chen, P. Yan, and Y. Hu, "Dam foundation excavation techniques in China: a review," Journal of Rock Mechanics and Geotechnical Engineering, vol. 5, no. 6, pp. 460-467, 2013.

[39] X. Wang, Y. Liu, Z. Tao, W. Wang, and Q. Yang, "Study on the failure process and nonlinear safety of high arch dam and foundation based on geomechanical model test," Engineering Failure Analysis, vol. 116, Article ID 104704, 2020. 
[40] Y. Y. Luo and S. Z. Shen, "Application of controlled blasting technology in dam foundation excavation of Longtan hydropower station," Hongshui River, vol. 22, no. 3, pp. 43-45, 2003, in Chinese.

[41] L. Zhao, M. Tao, and G. Wu, "The excavation technique at the trenches of the dam abutment on left bank of the Xiluodu hydropower station on the Jinshajiang river," in Proceedings of the 9th National Conference on Engineering Blasting, pp. 203-210, Metallurgical Industry Press, Beijing, China, 2008, in Chinese.

[42] S. J. Guan and X. C. Yuan, "Excavation construction and supervision for dam foundation of Jinping dam," Yangtze River, vol. 40, no. 18, pp. 61-63, 2009, in Chinese.

[43] S. Zhu, "Study on relaxation property of rock mass excavation on left bank dam foundation of Baihetan hydropower project," Master's thesis, Hohai University, Nanjing, China, 2019. 